\title{
Método para quantificar pequenas áreas (perfil do solo) utilizando SIG
}

\section{A method to account small areas (soil profiles) using GIS}

\author{
Osvaldo Coelho Pereira Neto ${ }^{1 *}$; Maria de Fátima Guimarães ${ }^{2}$
}

Resumo

O Sistema de Informação Geográfica - SIG é uma tecnologia que muito auxilia a confecção e análise de mapas do espaço físico-territorial e ambiental. Este trabalho visa propor um método para quantificar áreas de tamanho pequeno, como as unidades morfologicamente homogêneas (UMH) de um perfil cultural do solo, utilizando o programa computacional Arcview8. As UMH's foram facilmente identificadas e suas áreas quantificadas por profundidade.

Palavras-chave: Geoprocessamento, perfil cultural, unidades morfologicamente homogêneas

\begin{abstract}
Geographic Information System - GIS is a technology developed to generate and to analyze spatial information on several thematic areas. This work provides a method to generate and to quantify small extension areas, like morphological homogeneous units (MHU) of a soil cultural profile, using the software Arcview8. The MHU were easily identified and their areas quantified by depth level.
\end{abstract}

Key words: Geocoding, soil cultural profile, morphological homogeneous units

O uso de Sistemas de Informações Geográficas (SIG) é uma realidade em nível mundial, em qualquer atividade na qual haja a necessidade de analisar, mapear e quantificar áreas. Inúmeros trabalhos surgem a cada dia analisando aspectos diversos, como ambientais, agronômicos e urbanos, produzindo mapas de porções da superfície do planeta com temas variados: mapas de uso do solo, de cobertura vegetal, de declividade, de ocupação urbana ou qualquer outro que seja objeto de estudo, geralmente abrangendo áreas grandes, cujas unidades vão do $\mathrm{m}^{2}$ ao $\mathrm{km}^{2}$.

Este estudo está inserido em um novo contexto possível para o SIG, introduzindo a possibilidade de se trabalhar em áreas pequenas, comumente expressas em $\mathrm{cm}^{2}$ ou $\mathrm{mm}^{2}$ como, por exemplo, um perfil de solo.

Esta proposta metodológica vai ao encontro da necessidade de pesquisadores na área de Conservação de Solos e Meio Ambiente de quantificar as estruturas homogêneas do perfil do solo, tanto de forma relativa (percentual) quanto absoluta (métrica). O termo "Perfil do Solo", ou "Perfil Pedológico" é, na área agronômica, amplamente conhecido e divulgado. Porém, não deve ser confundido e tomado como sinônimo do termo "Perfil Cultural do Solo". Manichon e Gautronneau (1996) afirmam que as informações obtidas da interpretação de ambos diferem, e não tem a mesma finalidade.

\footnotetext{
1 Engenheiro Agrônomo, Doutorando, Docente da Universidade Estadual de Londrina-PR. E-mail: coelho@uel.br

2 Engenheiro Agrônomo, Doutora, Docente da Universidade Estadual de Londrina-PR. E-mail: mfatima@uel.br

* Autor para correspondência.
} 
Segundo eles, o Perfil Pedológico "busca identificar os processos de formação dos solos, a partir da rocha-mãe, mediante fatores bioclimáticos". O Perfil Cultural, por sua vez, é "o conjunto dos horizontes do solo individualizados pela intervenção de implementos agrícolas, pelo comportamento das raízes das plantas do local e pela influência dos fatores naturais (clima)".

O método do perfil cultural é usado no Brasil desde a década de 90, e permite destacar diferentes unidades morfológicas no perfil conforme o manejo adotado. Com isso, pode-se entender e, consequentemente, intervir nos processos de compactação e selamento do solo, auxiliar na escolha da técnica de amostragem de solo mais apropriada, orientar a análise das interações bio-físico-químicas do solo. (FREGONEZI et al., 2001; TAVARES FILHO et al., 1999).

Tamia et al. (1999) denominam as diferentes estruturas de um perfil cultural como sendo Unidades Morfologicamente Homogêneas (UMH). Essas UMH's podem ser quantificadas pelo uso de Sistemas de Informação Geográfica (SIG), que são sistemas computacionais capazes de armazenar, recuperar, integrar, manipular e visualizar diferentes informações da superfície terrestre. Estes dados geográficos descrevem objetos do mundo real em termos de posicionamento com relação a um sistema de coordenadas (BURROUGH, 1986; SMITH et al., 1987). Por isso, esses sistemas podem ser utilizados em estudos relativos ao meio ambiente e aos recursos naturais, na pesquisa de previsão de determinados fenômenos ou no apoio às decisões de planejamento, considerando o fato de que os dados armazenados representam um modelo do mundo real (BURROUGH, 1986).

De acordo com Alves et al. (1988), os principais objetivos do SIG são: a) integrar, numa única base de dados, informações que representam vários aspectos do estudo de uma região, como altimetria, uso do solo e rede de drenagem; b) permitir a entrada de dados de diversas formas, como vetores ou imagens; c) combinar as várias informações, através de algoritmos de manipulação, gerando informações para diversos fins; d) gerar relatórios e documentos gráficos de diversos tipos, como mapas e dados tridimensionais.

Dentre vários programas computacionais existentes nessa linha tecnológica, o ARCVIEW é considerado um dos líderes no mercado de desenvolvimento de projetos em SIG devido a sua versatilidade e grande interatividade com o usuário, além de ser um completo sistema integrado e modular para criação, gerenciamento e análise de dados geográficos.

Deste modo, o presente trabalho tem por objetivo apresentar uma proposta metodológica para quantificar as estruturas homogêneas de um perfil de solo gerado pelo método do Perfil Cultural a partir do uso de um SIG. Insere-se, portanto, uma nova dimensão à análise espacial, pois o SIG é desenvolvido para trabalhar com áreas ao longo da superfície terrestre, enquanto que perfis de solo são áreas vistas de outra perspectiva, tipo secções verticais.

Os materiais utilizados foram:

a) Mapa de perfil cultural de solo em escala 1:2 sob cultura de milho, confeccionado em trincheira aberta perpendicularmente à linha de plantio, gerando um perfil com comprimento de 1,4 m e profundidade de $0,50 \mathrm{~m}$. As estruturas homogêneas foram identificadas de acordo com a metodologia do Perfil Cultural (MANICHON; GAUTRONNEAU, 1996), adaptada por Tavares Filho et al. (1999);

b) Programa computacional ARCVIEW 8 (plataforma Windows);

c) Equipamento computacional: microcomputador com processador Pentium 2,8 MHz, $256 \mathrm{Mb}$ de RAM, HD de $40 \mathrm{~Gb}$.

O mapa do perfil do solo foi escaneado e importado para o Arcview, procedendo-se o seu georreferenciamento. Este foi feito com pontos de controle situados nos quatro cantos do perfil, com unidade linear em centímetros (de 0 a $50 \mathrm{~cm}$ na altura do perfil e de 0 a $140 \mathrm{~cm}$ no seu comprimento). 
$\mathrm{Na}$ escolha da projeção cartográfica, utilizou-se a opção "Desconhecida", pois tais projeções são concebidas como sistemas de coordenadas definidas a partir de modelos geodésicos esferoidais ou elipsoidais para a superfície terrestre, sendo inadequados para representar um perfil de solo, que é perpendicular a essa superfície.

Foram confeccionados três mapas no Arcview, sendo um com as UMH's do perfil, outro com as profundidades e um terceiro somente com o perímetro do perfil. Este último serviu como molde para o recorte dos dois primeiros, para que tivessem exatamente o mesmo tamanho. A seguir foi feita a intersecção do mapa das UMH's com o das profundidades, obtendo-se um quarto mapa com as áreas de cada UMH por profundidade do perfil.

Os mapas digitalizados são apresentados na Figura 1, com as linhas da "Profundidade" sobrepostas ao tema "Perfil".

Na Tabela 1 são apresentados os resultados da quantificação das estruturas do perfil de acordo com a profundidade.

\section{Perfil Cultural X Profundidade, sob plantio de milho.}

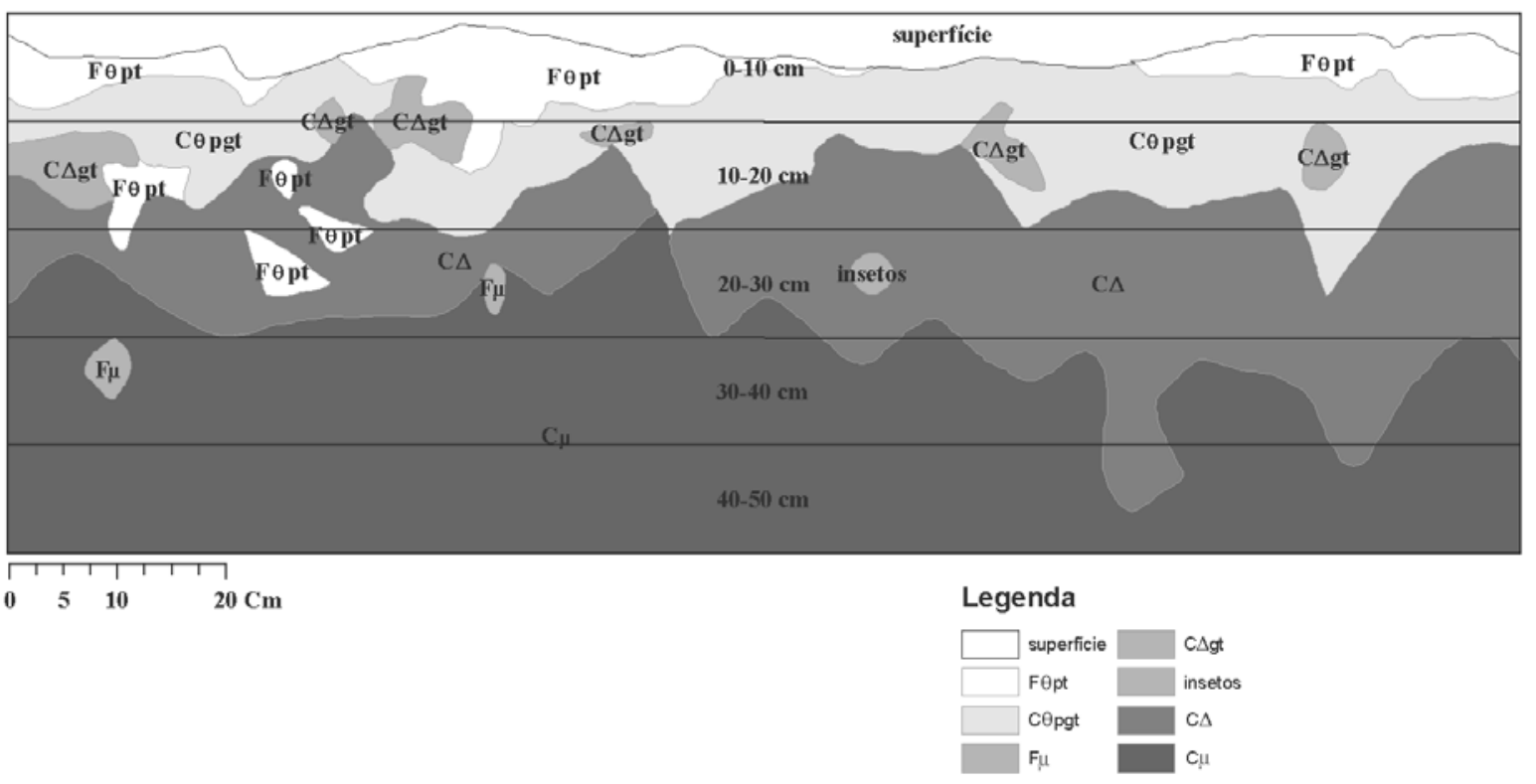

Figura 1. Esquema demonstrativo dos planos de informação "perfil" e "profundidade", sobrepostos. ( $F=$ volume de solo fissurado; $\mathrm{C}=$ volume de solo contínuo; $\Delta=$ torrões compactados; $\mu=$ torrões porosos; $\varnothing=$ intermediário entre $\Delta \mathrm{e} \mu ; \mathrm{pt}=$ pequenos torrões; $\mathrm{gt}=$ grandes torrões; $\mathrm{pgt}=$ presença de $\mathrm{pt} \mathrm{e} \mathrm{gt})$. 
Tabela 1. Matriz resultante do cruzamento dos planos de informações analisados (o valor da área de cada UMH em

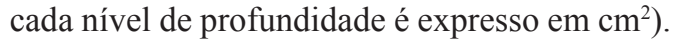

\begin{tabular}{crrrrrr}
\hline UMH & \multicolumn{7}{c}{ PROFUNDIDADE $(\mathrm{cm})$} & & \\
& 0 & $10-20$ & $20-30$ & $30-40$ & $40-50$ & Total \\
\hline superfície & 484,88 & 0 & 0 & 0 & 0 & 484,88 \\
FФpt & 424,91 & 57,97 & 34,11 & 0 & 0 & 516,99 \\
CФpgt & 456,54 & 676,05 & 23,10 & 0 & 0 & $1.155,69$ \\
C $\Delta$ gt & 27,58 & 139,61 & 0 & 0 & 0 & 167,19 \\
C $\Delta$ & 0,72 & 532,84 & $1.035,97$ & 230,12 & 38,82 & $1.838,47$ \\
insetos & 0 & 0 & 11,52 & 0 & 0 & 11,52 \\
F $\mu$ & 0 & 0 & 7,61 & 15,77 & 0 & 23,38 \\
C $\mu$ & 0 & 2,92 & 282,68 & $1.156,03$ & $1.360,23$ & $2.801,86$ \\
\hline Total & $1.394,63$ & $1.409,39$ & $1.394,99$ & $1.401,92$ & $1.399,05$ & $6.999,98$ \\
\hline
\end{tabular}

$\mathrm{UMH}=$ Unidades Morfologicamente Homogêneas; $\mathrm{F}=$ volume de solo fissurado; $\mathrm{C}=$ volume de solo contínuo; $\Delta=$ torrões compactados; $\mu=$ torrões porosos; $\varnothing=$ intermediário entre $\Delta \mathrm{e} \mu ; \mathrm{pt}=$ pequenos torrões; $\mathrm{gt}=$ grandes torrões; pgt $=$ presença de $\mathrm{pt}$ e gt).

Como o comprimento do perfil é de $140 \mathrm{~cm}$ e a profundidade é subdividida em 5 camadas de $10 \mathrm{~cm}$, tem-se que cada camada deveria ter $1400 \mathrm{~cm}^{2}$ de área, o que não acontece, estando os valores totais oscilando em torno disso. Este fato provavelmente se deve a digitalização manual do dado analógico (mapa em papel) para torná-lo digital. Isto pode incorrer em erro devido às imperfeições do papel ou ao próprio manuseio do operador; por melhor e mais exímio que este seja na aquisição de dados por digitalização, serão somados erros, independente do cuidado que o mesmo tenha.

Os trabalhos da literatura que utilizam o método do Perfil Cultural apresentam, em seus resultados, descrições feitas a partir de análises físico-químicas do solo e/ou de observações morfológicas feitas no perfil (MULLER et al., 2001; FREGONEZI et al., 2001). A metodologia proposta neste trabalho procura instalar mais um conceito analítico a esse processo, deixando de ser produto de mera observação, mas podendo ser alvo de comparações com métodos diferentes como, por exemplo, amostragens de solo em diferentes profundidades.
Assim, a possibilidade de quantificar as UMH's por profundidade permitirá inserir as avaliações dos Perfis Culturais para diferentes tipos de manejo agrícola, os quais interferem diferentemente nas camadas do solo. Com isso, na análise do perfil poderão ser incluídos os dados de área das diferentes UMH's em tratamentos estatísticos.

Esta metodologia espera auxiliar os estudiosos nas diversas áreas do conhecimento, cuja tônica seja o uso da tecnologia SIG para quantificar áreas inferiores às trabalhadas até então, nos diversos projetos elaborados para grandes áreas. Nesse contexto, já existem trabalhos sendo desenvolvidos para monitorar o crescimento vegetativo de plantas olerícolas, mostrando a diversidade de aplicações dessa tecnologia extremamente versátil.

\section{Conclusão}

A metodologia proposta mostrou-se válida e adequada para quantificar estruturas homogêneas de um perfil cultural conhecido. 


\section{Referências}

ALVES, D. S.; ERTHAL, G. J.; CÂMARA, G.; FELGUEIRAS, C. A.; PAIVA, J. A. C.; OLIVEIRA, E.; DIAS, L. A. V.; GODOY, M.; ABRAHÃO, A. Sistema de informação geográfica. In: CONGRESSO NACIONAL DE INFORMATICA, 21., 1988, Rio de Janeiro. Anais... Rio de Janeiro: SUCESU, 1988. v. 2.p. 915-920.

BURROUGH, P. A. Principles of geographical information systems for land resources assessment. New York: Oxford University, 1986.

FREGONEZI, G.A.F; BROSSARD,M.; GUIMARÃES, M. F.; MEDINA, C. C. Modificações morfológicas e físicas de um latossolo argiloso sob pastagens. Revista Brasileira de Ciência do Solo, Viçosa, v.25, n.4, p.1017-1027, out./ dez. 2001.

MANICHON, H.; GAUTRONNEAU, Y. Guia metodica del perfil cultural. La Paz: IBTA/ORSTOM, 1996

MULLER, M. M. L.; GUIMARÃES, M. F.; DESJARDINS, T.; MARTINS, P. F. S. Degradação de pastagens na Região Amazônica: propriedades físicas do solo e crescimento de raízes. Pesquisa Agropecuária Brasileira, Brasília, v.36, n.11,p.1409-1418, 2001.
SMITH, T. R; MENON, J. L.; STARR, S.; ESTES, J. E. Requirements and principles for the implementation and construction of large-scale geographic information system. International Journal of Geographical Information System, London, v.1, n.1, p.13-21, 1987.

TAMIA, A.; MOREAU, R; FORTIER, M; YORO, G. Influence du travail du sol sur l'évolution physique d'un sol forestier ferrallitique après défrichement motorisé. Étude et Gestion des Soils, Paris, v.6, n.1, p.27-39, 1999.

TAVARES FILHO, J.; RALICH, R.; GUIMARÃES, M. F.; MEDINA, C. C, BALBINO, L. C.; NEVES, C. S. V. J. Método do perfil cultural para avaliação do estado físico de solos em condições tropicais. Revista Brasileira de Ciência do Solo, Campinas, v.23, N.2, p.393-399, 1999. 